\title{
PANOPHTHALMITIS DUE TO AN ORGANISM OF THE BACILLUS SUBTILIS GROUP*
}

\author{
BY \\ ROBERT DAVENPORT AND CHARLES SMITH \\ Institute of Ophthalmology, London
}

THE first recorded series of cases of panophthalmitis due to Bacillus subtilis was that of Poplawska (1891), who described eight cases which followed perforating injuries, and 10 years later Römer (1901) described a case of post-operative infection. Reviewing the ocular infections due to these organisms, François (1934) collected forty cases from the literature; other cases have been reported by Greenspon (1918), Motolese (1936), and Reese and Khorazo (1943). In all these cases the organism was described as Bacillus subtilis, probably owing to the confusion that existed in the classification of this group of organisms, and no further identification was attempted. Wilson and Miles (1946) include all the pathogenic strains of this group, other than Bacillus anthracis, under the name of pseudo-anthrax bacilli or Bacillus anthracoides: the one exception to this classification is the Bacillus subtilis which according to them may be pathogenic in the eye but nonpathogenic in extra-ocular tissues and in laboratory animals. More recently Bergey (1948) has emphasized the confusion that exists in this group and has proposed a more rational basis for the identification of individual species. Chu (1949) suggested that many of the organisms which gave rise to infections were strains of Bacillus cereus and that the toxin which this organism produced might be responsible for their pathogenicity.

An outstanding feature of the ocular infections caused by these organisms is their fulminating character, the onset of symptoms occurring between 6 and $24 \mathrm{hrs}$ of injury in most cases. The following case which was typical of those previously described provided the material for a more complete bacteriological identification of the organism isolated, and it has been possible to show that the organism is not a $B$. subtilis, but a closely allied organism, namely $B$. cereus.

\section{Case Report}

The patient, a Lebanese merchant, aged 29, living on the Gold Coast, was watching a repair to his motor car when he was struck in the right eye by a foreign body, while the mechanic was tapping the gear box with a hammer. The injury occurred at about 10.30 a.m. on January 19, 1952. A small haemorrhage was noticed on the outer part of the globe and although he felt no pain he went to the Government Hospital. He was seen at about 2 p.m. by the ophthalmic specialist and was given hourly drops (? sulphonamide), but the presence of a retained intra-ocular foreign body was suspected.

* Received for publication March 25, 1952. 
By 7 p.m. that day he was in pain and vision had begun to fail. At 10 p.m. the eye was 'blind', and from this and the inflamed appearance of the eye he realized that it was irreparably damaged. He was advised to get an air passage to London, but owing to a plane cancellation could not leave until January 21, and did not arrive at Moorfields until January 22, 1952. During the delay in reaching London the inflammation became worse and the eye was " bleeding".

On admission to hospital he was febrile and somewhat exhausted but his general condition was good. There was gross chemosis and swelling around the right eye which was proptosed and obviously hopelessly infected. The centre of the opaque cornea had broken down and blood with a little thin pus was oozing from the necrotic opening.

$X$-ray examination showed the presence of an opaque intra-ocular foreign body; this was removed by a hand magnet and the eye eviscerated. The sclera was much thickened and the globe filled by an almost solid coagulum representing the intra-ocular contents. Cultures were taken from the discharge through the corneal perforation and from the posterior part of the intra-ocular contents.

Aureomycin treatment was started and the subsequent settling was rapid and complete.

\section{Bacteriology}

Cultures taken from the eye during evisceration gave a heavy growth of an aerobic spore-bearing organism, no other bacteria being present. The bacteria were Gram-positive, motile, and non-capsulate; they were about $1 \times 3-5 \mu$ in size and frequently formed short chains. The colonies were of a buff colour, with a rough surface and an irregular border, but on well-dried medium were not rhizoid. On blood agar plates there was a wide zone of $\beta$-haemolysis around the colony.

The organism was resistant to penicillin and sulphonamides but sensitive to aureomycin and streptomycin.

A culture from the eye drops used before arriving in England gave a heavy growth of $B$. coli. No aerobic spore-bearing organisms were present.

Biochemical Reactions. - The organism grew readily on simple media, but only a slight growth was found when citrate was used as the only source of carbon. Glucose, maltose, saccharose, dextrin, and starch were fermented in $24 \mathrm{hrs;} \mathrm{there}$ was a later fermentation of salicin, but lactose, xylose, and arabinose were not fermented after 7 days' incubation. Litmus milk was peptonized and gelatin liquefied and Nagler's reaction was positive. There was no growth in MacConkey broth, and the Voges-Proskauer and methyl red reactions were negative.

Dr. H. P. Chu of the Institute of Animal Pathology, Cambridge, kindly performed tests for the production of lecithinase and these were positive.

Pathogenicity.-Suspensions of the organisms in nutrient broth containing between $10^{7}$ and $10^{8}$ organisms per $\mathrm{ml}$. were injected into adult albino mice in doses of $0.5 \mathrm{ml}$. Seven of the inoculated mice died in $18 \mathrm{hrs}$ and at post mortem there were haemorrhagic peritoneal and pleural exudates and gross dilatation of the small intestines which were distended by gas. Cultures from the blood, peritoneum, spleen, and kidneys all gave a pure growth of the bacterium.

The remaining mouse became moribund on the 4th day and post-mortem examination revealed an extensive pneumonic consolidation of the lung and dilatation of the small intestines. Cultures from the lung were sterile and no 
bacteria could be found in sections, and it is possible that the consolidation may have been due to the activation of one of the endemic mouse pneumonia viruses.

An intraperitoneal injection into mice of $0.5 \mathrm{ml}$. of a suspension of $10^{6}-10^{7}$ organisms per ml. caused one septicaemic death in $24 \mathrm{hrs}$ and one death due to pneumonic consolidation of the lung after 5 days. The two survivors showed no signs of infection but cultures from the peritoneum and spleens at post mortem, 7 days after inoculation, grew a few colonies of $B$. cereus. A tenfold dilution of this suspension produced no lesions in a group of four mice when $0.5 \mathrm{ml}$. was injected intraperitoneally, and cultures at post mortem were sterile.

When $0.1 \mathrm{ml}$. of a suspension of the bacillus containing $10^{7}$ organisms per $\mathrm{ml}$. was injected into the anterior chamber of a rabbit's eye, an acute inflammatory reaction developed within $6 \mathrm{hrs}$, and there was severe chemosis and iritis in $24 \mathrm{hrs}$. The reaction settled down quickly and by the 4th or 5th day after injection the eye returned to normal. When the same quantity of bacteria was injected into the vitreous, a haemorrhagic panophthalmitis developed within $18 \mathrm{hrs}$; sections showed the vitreous to be filled with Gram-positive bacilli.

Identification of the Organism.-Since Chu (1949) suggested that the pathogenic airborne spore-bearing bacilli were probably members of the $B$. cereus species and not $B$. subtilis, it seemed important to make certain of the identity of the present strain. The classification used to identify the bacillus was that of Bergey (1948). The important points which separate this bacillus from $B$. subtilis are its size, colony form, and staining when grown in glucose medium. Thus it is larger than B. subtilis, which is normally $0.7 \times 2-3 \mu$, the colony is not rhizoid, and a Gram stain from glucose medium shows much vacuolation, which according to Bergey (1948) is not found with subtilis strains.

Some other features are unlike typical Bacillus subtilis strains: the motility is sluggish and gives an impression of deliberation very unlike the rapid movements seen with subtilis, and the digestion of gelatin is much more rapid with this organism than it is with Bacillus subtilis.

The species to which this bacillus is most closely allied is Bacillus cereus, the chief discrepancy between it and the description of Bergey (1948) being that it gives a negative Voges-Proskauer reaction, while classical strains give a positive reaction.

\section{Discussion}

Infections due to aerobic spore-bearing organisms are rare, but in man these organisms may produce a particularly fulminating type of panophthalmitis when entering the eye, usually as a sequel to penetrating injuries. Considering the great frequency of perforating injuries, many of which are likely to be contaminated with organisms of this group, the rarity of these infections is remarkable. Two hypotheses can be put forward to explain those cases which do occur:

(i) the infection is related to a dosage factor, panophthalmitis developing only when a massive inoculum enters the eye,

(ii) the power to produce such an infection is restricted to an uncommon member of this group of organisms. 
The evidence in favour of the first hypothesis is that even with a toxinproducing organism, such as Bacillus cereus, a large inoculum is needed to set up an infection. The alternative theory that these infections are due to a single species of organism was put forward by Chu (1949), when he showed that strains of $B$. cereus produced a toxin, lecithinase, similar to the toxin of Cl. Welchii. This is the more attractive theory, but the evidence for it is not conclusive in cases of panophthalmitis, as $B$. cereus has never been identified in such infections before the present case and the strains previously isolated have not been tested for lecithinase production. There are, however, points which suggest that the theory may be correct:

(i) Greenspon (1918) isolated pathogenic bacilli from two cases of panophthalmitis and also from the operating theatre in which the infections occurred, but was unable to demonstrate pathogenicity in any Bacillus subtilis strain isolated from other sources, even when they were injected into the vitreous.

(ii) There is also a close similarity in morphology and pathogenicity between Bacillus cereus and the organisms in the cases reviewed by François (1934) which suggests that these bacteria are of the same species.

Against these observations must be set those of Kodama (1910), who isolated a bacterium from dust which could cause panophthalmitis in rabbits, but it should be noted that the organism he isolated came from a workshop in which a case of panophthalmitis had occurred following penetrating injury. Furthermore, the description of the organisms isolated in some cases differs widely from that of a classical B. cereus; thus Römer (1901)-described a filamentous organism, difficult to culture, Reese and Khorazo (1943) say their bacillus was non-motile, Kodama (1910) described an organism which corresponds more closely to a classical $B$. subtilis than to a $B$. cereus.

\section{Summary}

A case of panophthalmitis due to Bacillus cereus is described. This organism has not been isolated previously in such a condition and it is suggested that many of the cases of panophthalmitis said to be due to Bacillus subtilis may in fact be caused by this organism.

Bacillus cereus is an organism which produces a toxin, lecithinase, which is probably the reason of the fulminating nature of these infections.

\section{REFERENCES}

Bergey, D. H. (1948). “Bergey's Manual of Determinative Bacteriology”, 6th ed. Ed. R. S. Breed, E. G. D. Murray, and A. P. Hitchens. Baillière, Tindall, and Cox, London.

CHU, H. P. (1949). J. gen. Microbiol., 3, 255.

Françors, J. (1934). Bull. Soc. franç. Ophtal., 47, 423.

GreENSPON, E. A. (1918). Amer. J. Ophthal., sec. 3, 1, 316.

Kodama (1910). Klin. Mbl. Augenheilk., 48, (i), 624.

Motolese, F. (1936). Boll. Oculist., 15, 1023.

PoplawsKa, S. (1891). Arch. Augenheilk., 22, 337.

Reese, A. B., and Khorazo, D. (1943). Amer. J. Ophthal., 26, 1251.

RÖMER, P. (1901). Ber. ophthal. Ges. Heidelberg, 29, 209.

Wilson, G. S., and Miles, A. A., eds. (1946). "Topley and Wilson's Principles of Bacteriology and Immunity ", 3rd ed. Arnold, London. 